\title{
化工企业火灾及爆炸原因分析及预防研究
}

李勋秀

浙江天为企业评价咨询有限公司

DOI:10.18686/bd.v2i10.1739

[摘 要] 化工工业发展在工业和人民居住生活中越来越重要,在现代化工生产过程中,使用的原料、中间体甚至产品本身 几乎都是易燃、易爆、强腐蚀、剧毒物质, 且生产大多在高温、高压、高速、腐蚀等严酷条件下完成, 危险因素多。文章论述了 化工企业安全生产的必要性、事故产生的原因和相应的预防措施。

[关键词] 化工企业; 火灾;爆炸;预防

\section{1 化工企业安全生产的必要性}

一个化工厂从建立到生产出产品。要经过很多环节, 包 括环境评价、产品和生产装置的安全性评价等。这些企业虽 然表面上可以获利,但实际会造成各种各样的隐患。因此, 目前国家仅有环保部门和安监部门来进行管理是远远不够 的。

安全生产是化工生产的前提, 由于化工生产品中易燃 易爆、有毒、有腐蚀性的物质多, 高温、高压设备多、工艺复 杂、操作要求严格,如果管理不当或者生产中出现失误, 就 可能发生火灾、爆炸、中毒或者灼伤等事故,影响到生产的 正常进行, 甚至毁灭整个工厂。无数事实告诉我们, 没有一 个安全的生产基础,现在化工就不吭能够健康正常的发展。

安全生产是化工生产的保障, 要充分发挥现代化工生 产的优势, 必须实现安全生产, 确保生产长期连续、安全的 运行。发生事故就会造成企业不能正常运行, 影响生产能 力, 造成一定的经济损失。安全生产是化工生产的关键, 化 工新产品的开发、新产品的试生产必须解决安全生产问题, 否则便不能进人实际生产。

\section{2 火灾爆炸事故的原因}

2.1 可燃气体泄漏。由于可燃气体外泄容易与空气形成 爆炸性混合气体, 因此, 可燃气体的泄漏就容易造成火灾爆 炸事故。可燃性气体泄漏有以下几种情况:(1)设备的动静密 封处泄漏。(2)设备管道腐蚀泄漏。(3)水封因断水, 未加水跑 气泄漏。(4)设备管道阀门缺陷或断裂造成泄漏。

这类事故大致是由于生产设备管理混乱，密封材料材 质或检修不合要求,操作维护不当, 在检修中未泄压却加外 力, 操作中巡回检查开停车不按操作规程进行等因素引起 的,因此,必须按原化工部规定的检修操作规程、无泄漏工 厂的标准以及设备动力管理条例等有关规定加以管理。对 已出现的泄漏, 及时发现, 及时消除, 暂不能消除的要有预 防措施,避免扩大或发生灾害事故。

2.2 系统负压, 空气与可燃气体混合。造成可燃性混合 气体情况有以下几种:(1)系统停车,停车后随温度。(2)下降 造成负压、吸人空气。(3)系统停水, 停水后水封水因泄漏失 去作用而导致空气吸人。(4)操作失误, 联系不当, 报警联锁
装置不全或失灵,造成气体抽送不平衡而至负压, 由敞口或 泄漏处吸人空气。(5)气体人口管线被杂物、结晶体或水堵 塞, 造成抽负, 由敞口或泄漏处吸人空气。(6)用空气作试压、 试漏,系统可燃物未清除干净、未加盲板,造成可燃气体与 空气混合。

这类事故大部分发生在气体输送岗位或与气体压缩有 关的岗位, 当发生在加压过程中时更加危险, 因为在爆炸性 混合气体中,一方面氧含量在增加, 另一方面在加压后, 爆 炸极限范围扩大,更容易发生事故。

2.3 系统生产时氧含量超标。氧含量超标, 可能在许多 部位出现,但究其原因集中在造气岗位, 通常由操作失误、 设备缺陷、人员违章、断油断汽或安全报警装置失灵所造 成,氧含量超标可能超出造气岗位范围而在脱硫、变换、压 缩等部位发生,应当引起特别重视。

2.4 系统串气。系统串气有 2 种情况:(1)高压串低压,形 成超压爆炸。(2)空气与可燃性气体互串形成化学性爆炸。

前一种情况大部分是由于操作失误及低压无安全附件 或附件失灵造成。如合成高压串低压液氨槽爆炸,合成高压 串低压再生系统爆炸等等。后一种情况大部分是由于盲板 抽堵错误, 用阀门代替盲板或误操作造成。如某设备动火, 内为空气,因系统未用盲板隔离,可燃气体由阀门漏人或有 人误操作打开关着的阀门, 使可燃气体进人正在动火的设 备,与空气混合形成爆炸性混合气体, 因而发生爆炸。

2.5 违章动火。违章动火有以下几点:(1)未申请动火证 又无动火安全知识,私自动火。(2)虽申请动火证但未置换彻 底或取样方法不对,分析结果错误。(3)动火安全措施考虑不 周。(4)动火现场安全条件未周密查看。(5)动火系统与其他系 统未彻底隔绝。(6)动火作业证私自变更安全措施或更改动 火时间。(7)不置换动火或未维持正压动火。

这类事故是化工火灾爆炸事故的重点。由于动火作业 技术性极强,管理要求较高, 因此安技部门应切实控制好, 以防事故的发生。

\section{3 火灾爆炸事故的预防措施}

3.1 控制消除危险性因素

(1)合理设计。在化工企业中,搞技术改造,结合大修进 
行小改革的机会较多, 在设计变更过程中, 要采用先进的工 艺技术和技术水平高、可靠性强的防火防爆措施, 采用安全 的工艺指标和合理的配管。

(2)正确操作,严格控制工艺指标。化工企业安全生产技 术规程是多年来安全生产的经验总结, 只要严格按着规程 进行作业, 严格控制工艺指标, 在规程规定的范围内超过指 标界限, 立即采取有效措施加以扭转, 而不是勉强维持, 就 能达到预想的安全结果。

(3)加强设备管理。火灾事故发生的一个重要原因,是生 产装置缺陷。设备状况好, 运行周期长, 检修量小, 事故隐患 少, 火灾爆炸发生率就低, 凡是设备管理好的单位, 安全生 产的条件也好。搞好设备管理的手段有: (1)贯彻计划检修, 提高检修质量, 实行双包制度。22加强压力容器的管理, 强 化监察和检测工作。(3)对于超期服役的设备或有不符合现 行法规规定的设备,一方面加强检测和监察,另一方面要有 计划地逐步更新换代。(4)设备的安全附件和安全装置要完 整、灵敏、可靠、安全好用,同时,要注意用比较先进的、可靠 性好的逐步取代老式的。(5)推广检测工具的使用，逐步把对 设备检查的方法从看、听、摸上升为用状态监测器进行, 使 之从经验检查变为直观化、数据化检查。

(4)提高自动化程度和使用安全保护装置的程度。随着 化工企业的发展, 不仅安全需要提高自动化程度, 而且从节 能降耗提高质量, 提高劳动生产率, 从而提高经济效益方面 都需要提高自动化程度。因为自动化程度的提高, 避免了超 温、超压、超负荷运行, 从而保证生产装置达到稳定、长周期 运行, 避免了事故的发生。多采用联锁保护装置, 可以提高 系统的安全性,一旦出理不正常情况, 有了联锁保护自动切 断或动作, 不仅可以防止事故的发生, 而且也遏止了事故的 暻延。当然, 在使用安全联锁保护装置时,首先, 应加强维护 保养,定期检查,保证灵敏可靠; 同时,不应降低对安全工作 的责任心, 不能因有了联锁装置而麻痹大意, 特别应重点保 护危险性大的部件。

(5)加强火源的管理。火灾爆炸事故的发生,一个很重要 的原因是缺少对火源的管理, 化工企业的火源一般有以下 几种:

(1)明火：主要是化工生产过程中的加热用火和维修用 火。

(2)摩擦与撞击。

(3)电气火花和静电火花。
(4)其他火源: 指高温表面可产生自燃的物质、烟头、机 动车辆、排气管等。加强上述四种火源的管理是避免火灾事 故的基本措施。

(6)加强危险品的管理。火灾爆炸危险品有以下几种: 爆 炸性物品, 氧化剂, 可燃和助燃气体, 可燃、助燃液体, 易燃 固体, 自燃物品和遇水燃烧物品。根据各类危险物品的性 质,按规定分门别类咜存保管。在它存保管中必须把好“三 关”,即人库验收关, 在库咜存关, 出库复验关。

3.2 防爆泄压措施

常用的防爆泄压装置有安全阀、防爆膜、防爆门、放空 阀、排污阀等,主要是防止物理性超压爆炸。安全阀应定期 校验, 选用安全阀时要注意使用压力和泄压速度。防爆膜和 防爆门的作用, 主要是避免发生化学爆炸时产生的高压, 防 爆膜和防爆门选用时应经过计算并选择合理的部件。放空 阀和排污阀是在紧急情况下作为卸压手段而使用, 但需要 人操作,因此,一定要保证灵活好用。

\section{3 防止火灾蔓延的措施}

防止火灾蔓延是防止火灾爆炸事故发生的一项重要措 施, 常用的阻火设施有: 切断阀、止逆阀、安全水封、水封井、 阻火器、挡火墙等。这些设施的作用是防止当火灾发生时火 焰的蔓延。如压缩机与各工段之间的切断阀、止逆阀、气柜 或乙炔发生器的安全水封, 甲醇放空管的阻火器.电缆间的 挡火墙。对这些设施，应当利用计划小修对其进行清理、检 查、维护、保养,以保证安全生产, 另一方面,在建筑上应采 用防火墙、防火门、防火堤、防火带以及合理的间距,采取耐 火等级厂房等措施。

\section{4 结语}

化工企业应重视火灾及爆炸事故的预防，在制订预案 时, 要把灭火和化学事故应急救援有机的结合起来, 对各种 可能产生的情况要准备充分, 只有这样, 才能切实提高职工 的处置各类事故的能力。

\section{[参考文献]}

[1]南侠展昭.化工企业火灾爆炸事故的常见原因分析 和预防措施[J].安全与健康,2018(3):22.

[2] 许知春. 浅谈化工企业火灾爆炸事故的预防措施 [J].化工安全与环境,2016(50):37.

[3] 贾云龙. 浅谈化工气体爆炸事故原因及救援措施 [J].房地产导刊,2017(2):29. 